\title{
SMILE: INTERPRETATION OF WP4 PTS TRANSIENT TYPE EXPERIMENT PERFORMED ON A CRACKED CYLINDER INVOLVING WARM PRE-STRESS
}

\author{
Dominique Moinereau * \\ EDF R\&D \\ Département MMC \\ Site des Renardières \\ 77818 Moret-sur-Loing Cedex, France \\ Phone: 331607367 90, Fax: 3316073 \\ 6559 \\ E-mail: Dominique.moinereau@edf.fr
}

\author{
Anna Dahl \\ $E D F R \& D$ \\ Département MMC \\ Site des Renardières \\ 77818 Moret-sur-Loing Cedex, France \\ Phone: 331607366 01, Fax: 3316073 \\ 6559 \\ E-mail: Anna.dahl@edf.fr
}

\author{
Yves Wadier \\ EDF R\&D \\ Département AMA \\ 1 Avenue du Général de Gaulle \\ 92141 Clamart Cedex, France \\ Phone: 33147655869 \\ E-mail:Yves.wadier@edf.fr
}

\begin{abstract}
The Reactor Pressure Vessel (RPV) is an essential component liable to limit the lifetime duration of PWR plants. The assessment of defects in RPV subjected to PTS transients made at an European level do not always account the beneficial effect of load history (warm pre-stress WPS). A 3-year Research \& Development program - SMILE - has been started in January 2002 as part of the $5^{\text {th }}$ Framework Program of the European Atomic Energy Community (EURATOM). The SMILE project - Structural Margin Improvements in aged embrittled RPV with Load history Effect - is one of a cluster of $5^{\text {th }}$ framework projects in the area of Plant Life Management. It aims to give sufficient elements to demonstrate, to model and to validate the beneficial WPS effect in a RPV integrity assessement. Within the framework of the project, an important experimental work has been conducted including WPS type experiments on CT specimens and a PTS type transient experiment on a large component. The WPS type experiment on the cylinder has been successfully conducted by MPA Stuttgart with a final brittle failure during the reloading. The present paper describes shortly the experiment and presents the corresponding analyses based on engineering methods, finite element elastic-plastic computations, and local approach to fracture. The results are in good agreement with the experimental observations. Very significant margins are underlined, with an effective important increase of the material resistance regarding the risk of brittle failure.
\end{abstract}

Keywords: Warm pre-stress, RPV, fracture mechanics, brittle failure 


\section{THE SMILE PROJECT AND THE WARM PRE-STRESS (WPS)}

The integrity of the reactor pressure vessel (RPV) of nuclear power plants (NPP) is essential to its safe operation. A hypothetical rupture of the vessel has the potential to cause a massive loss of coolant, overheating of the reactor core, and a subsequent major release of radioactivity to the environment. As part of the assurance of structural integrity, the RPV structural integrity analyses - based on fracture mechanics - consider the behavior of defects under normal and abnormal loading conditions to assess safety margins and component lifetimes as materials become degraded by irradiation and (or) thermal ageing. These analyses compare load and resistance terms to demonstrate that the crack driving force does not exceed the vessel material fracture toughness during all the transient, whatever the loading path (loading part and decreasing part of the transient).

In some Western countries (such as France), the structural integrity assessment of a RPV subjected to PTS transients doesn't take into account the potential beneficial effect of the load history ('warm pre-stress WPS') on the vessel resistance regarding the risk of brittle failure. Such approach has then some major consequences :

a potentially over-conservative assessment of the margins associated with the loading to which the component (RPV) is subjected

a potential economic penalty due to under-estimation of the component safe lifetime

A 3-year European Research \& Development project (SMILE) started in January 2002 as part of the $5^{\text {th }}$ Framework Programme of the European Atomic Energy Community (EURATOM) [1][2][3]. SMILE ('Structural Margin Improvements in aged-embrittled RPV with Load history Effects') is one of a 'cluster' projects in the area of Plant Life Management. It aims to demonstrate on specimens (small and large scales), to model and to validate the beneficial effect of the warm pre-stress in a RPV structural integrity assessment. Finally, this project aims to harmonize the different approaches to lay the basis for European codes and standards regarding the inclusion of the WPS effect in a RPV assessment.

All elements necessary to propose a methodology to account WPS in RPV assessment are gathered or obtained. This is done through experimental works on conventional fracture mechanics specimens (such as CT specimens) and a 'large-scale' component (cracked cylinder submitted to a PTS type transient), leading to a deep understanding of metallurgical and mechanical phenomena, and through numerical works and development (or improvement) of analytical and numerical models.

The warm pre-stress effect is well known. The beneficial effect of the load history ('warm pre-stress') on the vessel resistance regarding the risk of brittle failure can be summarized as follows (Fig. 1) :

- $\quad$ Brittle failure is impossible during the unloading of the vessel (decrease of the stress intensity factor $K_{J}$ versus temperature $T$, even if the loading path $K_{J}-T$ intersects the material fracture toughness curve)

- In case of a final reloading of the vessel at lower temperature, the brittle failure would be obtained with beneficial and substantial margins compared to material fracture toughness obtained on a 'virgin' material

A large overview of SMILE project is presented in [3]. The present paper shortly describes the PTS experiment and presents the corresponding analyses based on engineering methods, finite element elastic and elastic-plastic computations, and local approach to fracture. The results are in good agreement with the experimental result. Significant margins are underlined, with an effective significant increase of the material resistance regarding the risk of brittle failure.

\section{DESCRIPTION OF THE WPS VALIDATION TEST}

In order to demonstrate the WPS-effect on a 'representative' component under thermal shock conditions (PTS), a model vessel in the form of a cylinder containing a circumferential shallow crack has been tested by MPA Stuttgart under combined mechanical and thermal loading. Full information about this experiment can be found in papers [4][5].

The material used for the validation test is the WPS3 steel (17 MoV 84 mod. steel). In order to simulate an irradiated end of life RPV material, it was artificially degraded by special heat treatment. The wall thickness of the cylinder is $40 \mathrm{~mm}$ and the inside diameter $80 \mathrm{~mm}$ (Fig. 2).

The characterization of material properties has been fully achieved, including the evaluation of the fracture toughness behaviour by applying the Master curve approach $\left(\mathrm{T}_{0} \approx 140^{\circ} \mathrm{C}\right)$, using $\mathrm{CT}$ specimens.

The experiment is conducted as follow, and also described on Fig. 3 :

1/ Pronounced pre-loading in the upper shelf region of fracture toughness without ductile tearing initiation 
2/ Thermal shock by internal cooling of the specimen

3/ No fracture is expected during cooling phase, although crossing of fracture toughness $\mathrm{K}_{\mathrm{Ic}}$ and stress intensity factor $\mathrm{K}_{\mathrm{J}}$ (decreasing $\mathrm{K}_{\mathrm{J}}$ ) curves

4/ Final tensile reloading at room temperature up to final failure (expected brittle failure)

The initial crack was induced by spark eroding and fatigue cracking with internal pressure. The fatigue cracking was stopped at an averaged crack depth of $14.3 \mathrm{~mm}(13.5 \mathrm{~mm} \leq \mathrm{a} \leq 15.5 \mathrm{~mm})$. All the experimental conditions (Pressure, temperature, initial tensile load, crack depth ...) were previously defined during the design of the experiment, particularly to achieve the initial objectives.

Prior to this experiment, the experimental program contains also some WPS type experiments performed on conventional deep cracked CT fracture mechanics specimens, useful for the analysis of the validation test. Moreover all the experimental data obtained on the CT specimens have confirmed the beneficial effect of warm pre-stress, with a significant increase of the material fracture toughness regarding the risk of brittle failure initiation.

The experiment has been conducted by MPA Stuttgart on January 2004, with full success. The cylinder was first loaded at $2.1 \mathrm{MN}$ at $290^{\circ} \mathrm{C}$, then the load was kept constant during the whole cooling phase. No failure event occurred during the cooling crossing the fracture toughness curve in the transition region. Finally the reloading up to fracture was carried out at $37^{\circ} \mathrm{C}$ with a loading rate of $2 \mathrm{MN} / \mathrm{min}$. The failure of the cylinder was obtained during the final tensile re-loading of the cylinder, with a very significant high level of loading (5.3 MN)(Fig. 4). The destructive examination of the cylinder after the test was made by JRC Petten, MPA Stuttgart and CEA, including particularly the refined examination of the fracture surfaces. These examinations show a brittle failure of the cylinder at the end of the test, as expected (Fig. 4)[4][5].

\section{ANALYSES OF THE EXPERIMENT}

The interpretation of the WPS experiment on the cracked cylinder is performed by several partners of the project, involving a large panel of analyses :

- $\quad$ Engineering methods and models account for WPS, such as Chell, Chell \& Haigh, Wallin ...

- Global approaches based on the evaluation of the stress intensity factor (elastic $\mathrm{K}_{\mathrm{I}}$ or elastic-plastic $\mathrm{K}_{\mathrm{J}}$ ) and the comparison with the $\mathrm{K}_{\mathrm{Ic}}$ fracture toughness of the material

- $\quad$ Local approach of cleavage fracture based on Beremin model [6][7]

- $\quad$ Energy approach [8][9][10]

As the interpretation is still in progress, only the results obtained by EDF will be described in this paper. However, notice that other results are already available from CEA and Framatome ANP, very similar to EDF analyses presented in this paper.

The EDF interpretation of the experiment is conducted by 2D axi-symmetrical analyses (due to symmetry reasons) using Code_Aster finite element code developed by EDF, including non linear thermal analyses, elastic and elastic-plastic computations.

\section{INTERPRETATION BY GLOBAL APPROACH}

\subsection{Thermal analysis}

The first step of the analysis is the evaluation of the temperature field inside the specimen during the experiment and its comparison with experimental data coming from thermocouples located at various locations in the cylinder [4][5].

The comparison between numerical results and experimental values is shown in Fig. 5. As shown, a good agreement is obtained, particularly in the section near to the crack tip (a : $15 \mathrm{~mm})$.

\subsection{Evaluation of the stress intensity factor and comparison to the material $K_{1 c}$ fracture} toughness

The interpretation of the test is based on the computation of the elastic-plastic stress intensity factor $\mathrm{K}_{\mathrm{J}}$ and its comparison with the material $\mathrm{K}_{\mathrm{Ic}}$ fracture toughness (using Master curve methodology). The crack depth considered in these analyses is a : $15 \mathrm{~mm}$.

However, in order to validate the analyses (mesh and numerical simulations), an elastic analysis has first been conducted. Two different ways have been used for the evaluation of the elastic stress intensity factor $\mathrm{K}_{\mathrm{I}}$ :

by the 'displacements' method

using the energy release rate $\mathrm{G}$

$$
K=\sqrt{\frac{E_{(T)} G_{(T)}}{1-v^{2}}}
$$


The values of $\mathrm{K}_{\mathrm{I}}$, very close, validate thus the model and the simulation.

Afterwards, the elastic-plastic analysis has been conducted using an isotropic hardening (large strain and large displacements). The elastic-plastic stress intensity factor $\mathrm{K}_{\mathrm{J}}$, deduced from the computation of the $\mathrm{G}$ energy release rate, is compared to the material fracture toughness $\mathrm{K}_{\mathrm{Ic}}$ on Fig. 6, without any consideration of size effect (between 1T-CT specimens used fro $\mathrm{K}_{\mathrm{Ic}}$ measurements and the crack cylinder). Regarding the $\mathrm{K}_{\mathrm{Ic}}$ fracture toughness, all experimental data are included, in addition to $5 \%, 50 \%$ and $95 \%$ Master curve failure probabilities $\left(\mathrm{T}_{0}: 140{ }^{\circ} \mathrm{C}\right)$.

Figure 6 shows clearly very significant margins between $\mathrm{K}_{\mathrm{IC}}$ values and value of the SIF $\mathrm{K}_{\mathrm{J}}$ at the cylinder failure, with a higher resistance of the cylinder regarding the risk of brittle failure. The evolution, during the experiment, of the elastic-plastic SIF $\mathrm{K}_{\mathrm{J}}$ on the cylinder is clearly shown :

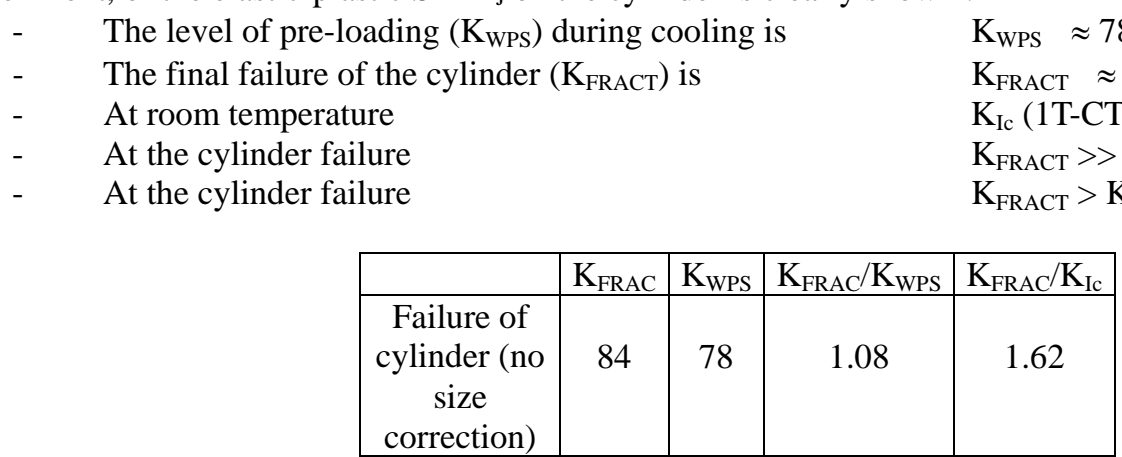

By comparing the respective behaviour of 1T-CT specimens and cracked cylinder, the beneficial effect of warm pre-stress is clearly underlined, by inducing a significant increase of the resistance of the cylinder regarding brittle failure initiation.

\subsection{Influence of size effect}

The same analysis is conducted, including now a size effect correction between the 1T-CT specimens and the cracked cylinder (crack front length limited to $100 \mathrm{~mm}$ for the cylinder). Several size corrections have been applied (Beremin correction, Wallin correction including a threshold $\mathrm{K}_{\min } \ldots$...). Only results obtained using Wallin size effect correction will be presented, but same tendencies are noticed with other size corrections. The 1T-CT $\mathrm{K}_{\mathrm{Ic}}$ values are kept similar, only the SIF $\mathrm{K}_{\mathrm{J}}$ of the cylinder is size corrected, in order to be compared to the behaviour of the 1T-CT specimens.

The results are presented on Fig. 7, with the comparison between $K_{J}$ and $K_{I c}$. Of course, due to size effect between the cylinder and the 1T-CT specimens, significant higher margins are obtained between $\mathrm{K}_{\mathrm{IC}}$ values and value of the SIF $\mathrm{K}_{\mathrm{J}}$ at the cylinder failure, with a higher resistance of the cylinder regarding the risk of brittle failure. The evolution, during the experiment, of the elastic-plastic SIF $\mathrm{K}_{\mathrm{J}}$ on the cylinder is again clearly shown :

The level of pre-loading ( $\left.\mathrm{K}_{\mathrm{WPS}}\right)$ during the cooling is

$$
\begin{aligned}
& \mathrm{K}_{\mathrm{WPS}} \approx 102 \mathrm{MPa} \cdot \mathrm{m}^{1 / 2} \\
& \mathrm{~K}_{\text {FRACT }} \approx 111 \mathrm{MPa} \cdot \mathrm{m}^{1 / 2} \\
& \mathrm{~K}_{\mathrm{Ic}}(1 \mathrm{~T}-\mathrm{CT})<52 \mathrm{MPa} \cdot \mathrm{m}^{1 / 2} \\
& \mathrm{~K}_{\text {FRACT }}>\mathrm{K}_{\mathrm{Ic}}(1 \mathrm{~T}-\mathrm{CT}) \\
& \mathrm{K}_{\text {FRACT }}>\mathrm{K}_{\mathrm{WPS}}
\end{aligned}
$$$$
\text { The final failure of the cylinder }\left(\mathrm{K}_{\mathrm{FRACT}}\right) \text { is }
$$$$
\text { At room temperature }
$$$$
\text { At the cylinder failure }
$$$$
\text { At the cylinder failure }
$$

\begin{tabular}{|c|c|c|c|c|}
\hline & $\mathrm{K}_{\mathrm{FRAC}}$ & $\mathrm{K}_{\mathrm{WPS}}$ & $\mathrm{K}_{\mathrm{FRAC}} / \mathrm{K}_{\mathrm{WPS}}$ & $\mathrm{K}_{\mathrm{FRAC}} / \mathrm{K}_{\mathrm{Ic}}$ \\
\hline $\begin{array}{c}\text { Failure of } \\
\text { cylinder } \\
\text { (with size } \\
\text { correction) }\end{array}$ & 111 & 102 & 1.09 & 2.13 \\
\hline
\end{tabular}

By comparing the respective behaviour of 1T-CT specimens and cracked cylinder, the beneficial effect of warm pre-stress is clearly underlined, by inducing a significant increase of the resistance of the cylinder regarding brittle failure initiation.

\section{4 comparison between cylinder and WPS type experiments on CT specimens}


The MPA Stuttgart has also conducted some WPS type experiments on CT specimens on the same material WPS3 (17 MoV 84 mod. steel). 1T, 2T and 4T-CT specimens have been tested, with several load paths $\mathrm{K}_{\mathrm{J}}-\mathrm{T}$ (LCF, LUCF and 'Real'), in conditions similar to the one applied on the cracked cylinder, previously described in the paper, particularly with the same level of pre-loading $\mathrm{K}_{\mathrm{WPS}}$.

Values of the SIF at fracture of all CT specimens, $\mathrm{K}_{\mathrm{FRACT}}$, are compared to the $\mathrm{K}_{\mathrm{J}}$ of cylinder at failure on Fig. 8. It appears that the values of the SIF at final failure, $\mathrm{K}_{\mathrm{FRACT}}$, are very closed between the cracked cylinder and the WPS type CT specimens.

\section{COMPLEMENTARY ANALYSES}

\subsection{Engineering models}

Engineering methods and models account for WPS (Chell, Chell \& Haigh, Wallin) will be also used in the analysis of the experiment. Unfortunately, the corresponding results are not yet available.

\subsection{Local approach to cleavage fracture (modified Beremin model)}

The 'local approach to fracture' is now well known, particularly the Beremin model for cleavage fracture [6]. To account notably unloading effects, this model has been modified ('modified Beremin model') [7] and implemented in Code_Aster finite element tool.

Starting from the original Beremin model, the failure probability expression is derived, considering both temperature dependence of the cleavage stress $\sigma_{\mathrm{u}}$ as well as unloading effects (integration on active plastic zone). The cumulative failure probability, at any given time $\mathrm{t}$, is given by :

$$
P_{r}=1-e^{\left(-\int_{V}\left[\max _{\{u<t, \dot{\mathrm{p}}(\mathrm{u})>0\}}\left(\frac{\sigma_{I}(u)}{\sigma_{u}(\theta(u))}\right)\right]^{m} \frac{d V}{V_{0}}\right)}
$$

where

$\mathrm{p}(\mathrm{u})=$ Cumulated plastic deformation

$\mathrm{V}_{0}=(50 \mu \mathrm{m})^{3}$

$\mathrm{m}=$ Weibull modulus

$\sigma_{u}(\theta)=$ Cleavage stress, temperature dependent

The model's parameters, $\mathrm{m}$ and $\sigma_{\mathrm{u}}$, are identified from the CT fracture toughness specimens. The Weibull modulus, $\mathrm{m}$, as well as the cleavage stress, $\sigma_{\mathrm{u}}$, have been fitted on these data through a maximum likelihood method. The corresponding results are reported in table 1.

Table 1 : Identification of Beremin parameters, $m$ and $u$,on WPS3 steel
\begin{tabular}{|c|c|c|c|c|c|}
\hline${ }^{\circ} \mathrm{C}$ & 22 & 130 & 150 & 200 & 300 \\
\hline $\begin{array}{c}\sigma_{\mathrm{u}} \\
\mathrm{MPa}\end{array}$ & 3204 & 3727 & 4026 & 5600 & 5600 \\
\hline $\mathrm{m}$ & & & & & \\
\hline
\end{tabular}

This model ('modified' Beremin model) has been applied to the interpretation of the experiment, with the evaluation of the cleavage failure probability of the cylinder during the transient. Main results are summarized on Fig. 9, showing the cumulative failure probability of the cylinder for 5\%, 50\% and $95 \%$ failure probability. This analysis is in agreement with the experimental result although probably too conservative.

\subsection{Energy approach}

The Francfort and Marigo theory, [8], generalises the Griffith theory and can predict initiation and sudden propagation of cracks, using a minimization principle. This theory has been extended to plasticity [9][10]. The $\Delta \mathrm{l}$ propagation minimizes the total energy of the structure including the energy dissipated during the propagation. An energy release rate called $G_{p}$ can then be defined for a crack or a notch, and the minimization of the energy is equivalent to the maximization of the function $G_{p}(\Delta \mathrm{l})$. The approach has been applied to the analysis of the shallow crack and the warm pre-stress effects [10]. 
The $G_{p}$ parameter is calculated as the maximum (with respect to $\Delta \mathrm{l}$, length of the notch propagation) of the integral over the area Ze (corresponding to the notch propagation) of the elastic energy, divided by $\Delta \mathrm{l}$, according to the formula :

$$
\mathrm{Gp}(\Delta \mathrm{l})=\max _{\Delta \mathrm{l}}\left[\left(\int_{Z e}(\text { we.dS })\right) / \Delta \mathrm{l}\right]
$$

where $w_{e}$ is the elastic energy. In order to compare the results obtained with the experimental ones and with those obtained with the Beremin model, we define a fracture probability, similarly to the fracture probability of the Beremin model, as function of $G_{p}$ and $G_{p c}$ (critical value of $G_{p}$ ) as follow :

$$
\mathrm{P}_{\mathrm{r}}=1-\exp \left[-\mathrm{a}\left(\mathrm{G}_{\mathrm{P}} / \mathrm{G}_{\mathrm{PC}}\right)^{\mathrm{m} / 2}\right]
$$

where "a" and "m" are material constant identified using the experimental results.

The comparison between the results obtained with the energy approach and the experimental results is presented on Fig. 10. Different hypotheses related to the material hardening have been considered : isotropic hardening (linear or bounded) and kinematics hardening. We can see that the influence of this hardening is not negligible. In order to make later comparisons between the energy and the Beremin approaches, the value of $\mathrm{T}_{0}=113^{\circ} \mathrm{C}$ (used to identify the Beremin parameters) is considered. The warm pre-stress effect is clearly obtained in all cases and the best result is obtained if the kinematics hardening is considered. At $95 \%$ of fracture probability, $\mathrm{K}_{\mathrm{J}}$ $\approx 75 \mathrm{MPa} \cdot \mathrm{m}^{1 / 2}$ is obtained, instead of $\mathrm{K}_{\mathrm{J}} \approx 89 \mathrm{MPa} \cdot \mathrm{m}^{1 / 2}$ (experimental result) which is a conservative result, the conservatism being reasonable. So the conclusion is that the energy approach gives satisfactory results and that it would be important to be able to identify the isotropic and kinematics parts of the material hardening.

\section{CONCLUSION}

A European project, SMILE, is in progress concerning the application of warm pre-stress in RPV assessment. Within the framework of this project, a PTS type transient - with a complex loading including WPS - has been conducted with full success at MPA Stuttgart on a cracked cylinder. As expected, no failure event occurred during the cooling. The failure of the cylinder, by cleavage, was finally obtained during the final tensile re-loading of the cylinder, with a high level of loading.

The interpretation of the experiment is in progress by several partners of the project. Nevertheless, some results are already available. Based on finite element elastic-plastic computations, several approaches have been used including the evaluation of the stress intensity factor $\mathrm{K}_{\mathrm{J}}$ and its comparison to the material fracture toughness $\mathrm{K}_{\mathrm{Ic}}$, the use of local approach to cleavage fracture ('modified Beremin model), and the application of the 'Energy approach'.

These analyses are in good agreement with the experimental failure of the cylinder, showing very significant margins due to WPS effect, with a higher resistance of the cylinder regarding the risk of brittle failure.

The beneficial effect of warm pre-stress is clearly underlined through this test on component, thus confirming previous experimental results on CT specimens on the same material with various experimental conditions.

A final synthesis of the analyses will be prepared in the next months when all results will be available, including also the application of engineering methods.

\section{ACKNOWLEDGMENTS}

SMILE is a European Commission DG RTD $5^{\text {th }}$ FP project in the area of Plant Life Management (Nuclear Fission). Within this framework, the authors wish to acknowledge the support of P. Manolatos as representative of the European Commission.

The authors also thank all partners of the project for their important contribution :
- $\quad$ D. Lidbury, J. Sharples (Serco Assurance)
- $\quad$ S. Chapuliot, T. Yuritzinn, B. Marini (CEA)
- D. Emond, L. Streibig (BCCN)
- $\quad$ K. Kerkhof (MPA Stuttgart)
- $\quad$ P. Budden (British Energy)
- Ph. Gilles (Framatome ANP)
- $\quad$ E. Keim, M. Ludwig (Framatome ANP GmbH)
- $\quad$ N. Taylor (Institute of Energy, JRC Petten)
- $\quad$ G. Nagel (E.ON) 


\section{REFERENCES}

[1] D. Moinereau et al.

'Structural Margin Improvements in Aged-embrittled RPV with Load History Effect (SMILE)'. EU Research in Reactor Safety, FISA 2003, 10-12 November 2003, Luxembourg

[2] D. Moinereau et al.

'SMILE : A European R\&D programme for the inclusion of warm pre-stress effect in a reactor pressure vessel structural integrity assessment, ICONE 11, $11^{\text {th }}$ International Conference in Nuclear Engineering, 20-23 April 2003, Tokyo, Japan

[3] D. Moinereau et al.

'SMILE : A European R\&D program for the inclusion of warm pre-stress effect in RPV assessment, SMIRT 18, $18^{\text {th }}$ International Conference on Structural Mechanics in Reactor Technology, August 7-12, 2005, Beijing, China [4] E. Roos, K. Kerkhof et al.

'SMILE. Test to the validation of the WPS effect with a cylindrical thick-walled specimen', $30^{\text {th }}$ MPA Seminar, 6-7 October 2004, Stuttgart, Germany

[5] K. Kerkhof, E. Roos et al.

'SMILE : Validation of the warm pre-stress effect with a cylindrical thick-walled specimen', ASME-PVP 2005 Conference, 17-21 July 2005, Denver, Colorado, USA.

[6] F. Mudry.

'A local approach to cleavage fracture', Proceedings of the International seminar on local approach of fracture, 3-4-5 June 1986, Moret-sur-Loing, France

[7] R. Masson et al.

'A modified Beremin model to simulate the warm pre-stress effect', Journal of Nuclear Engineering and Design, 216, pp 27-42, 2002

[8] Francfort G., Marigo J.J.

'Revisiting Brittle Fracture as an Energy Minimisation Problem'. J. Mech. Phys. Sol., 46, n8, (1998).

[9] Lorentz E., Wadier Y., Debruyne G.

'Mécanique de la rupture en présence de plasticité : définition d'un taux de restitution d'énergie'. C.R.A.S. t. 328, série IIb, 2000.

[10] Y. Wadier Y., M. Bonnamy

'The energetic approach of elastic-plastic fracture mechanics applied to the analysis of the warm pre-stress effect' ASME PVP, Cleveland - USA - 2003. 

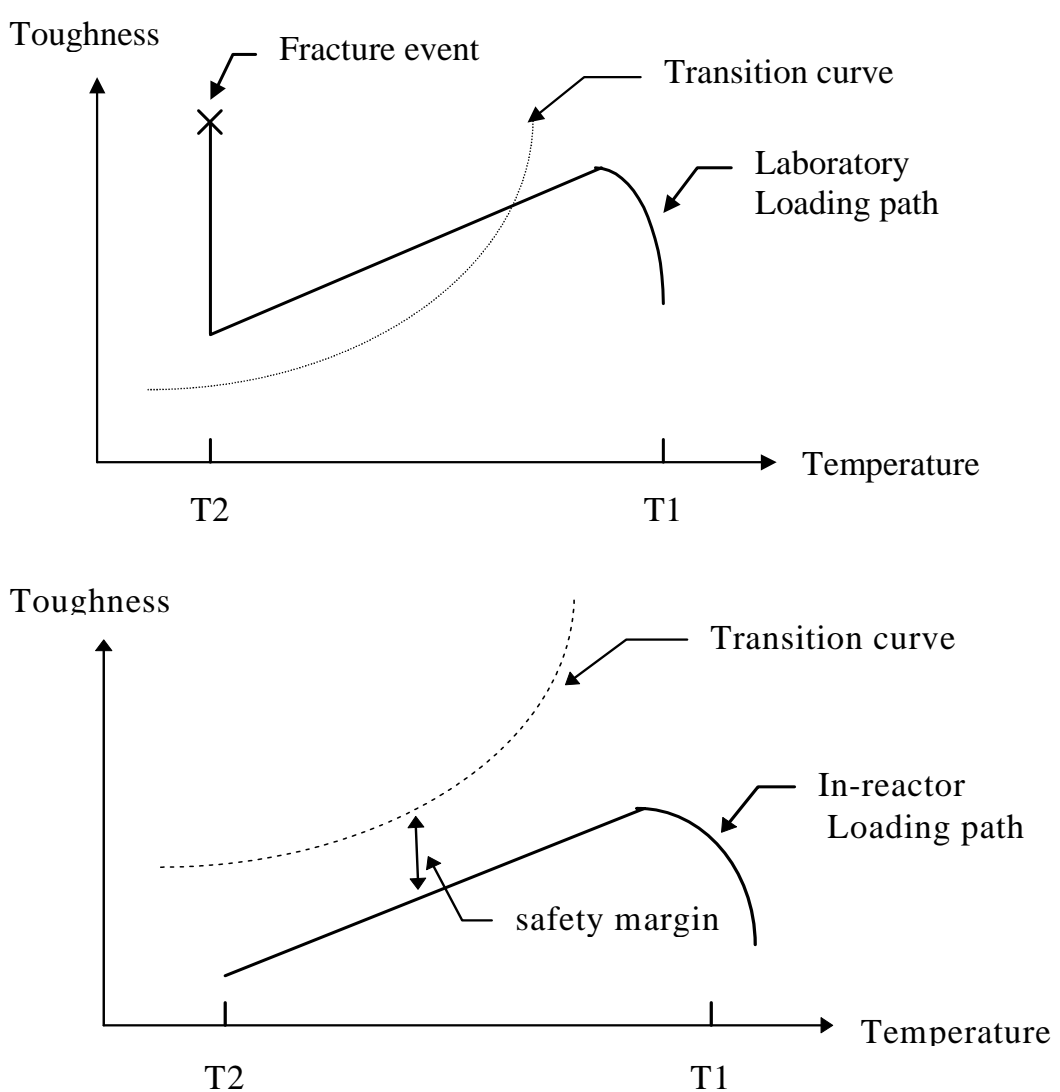

Fig. 1 - Schematic of warm pre-stress in RPV assessment

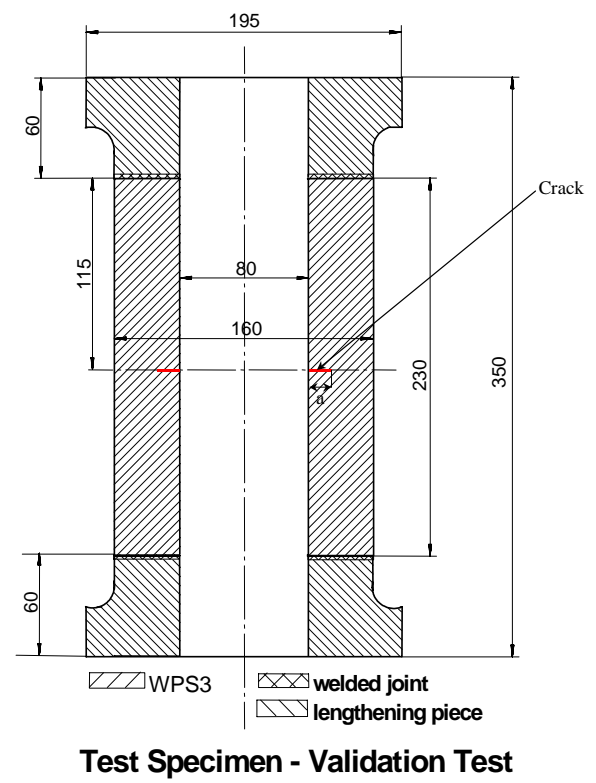

Fig. 2 - Geometry of the cylinder 


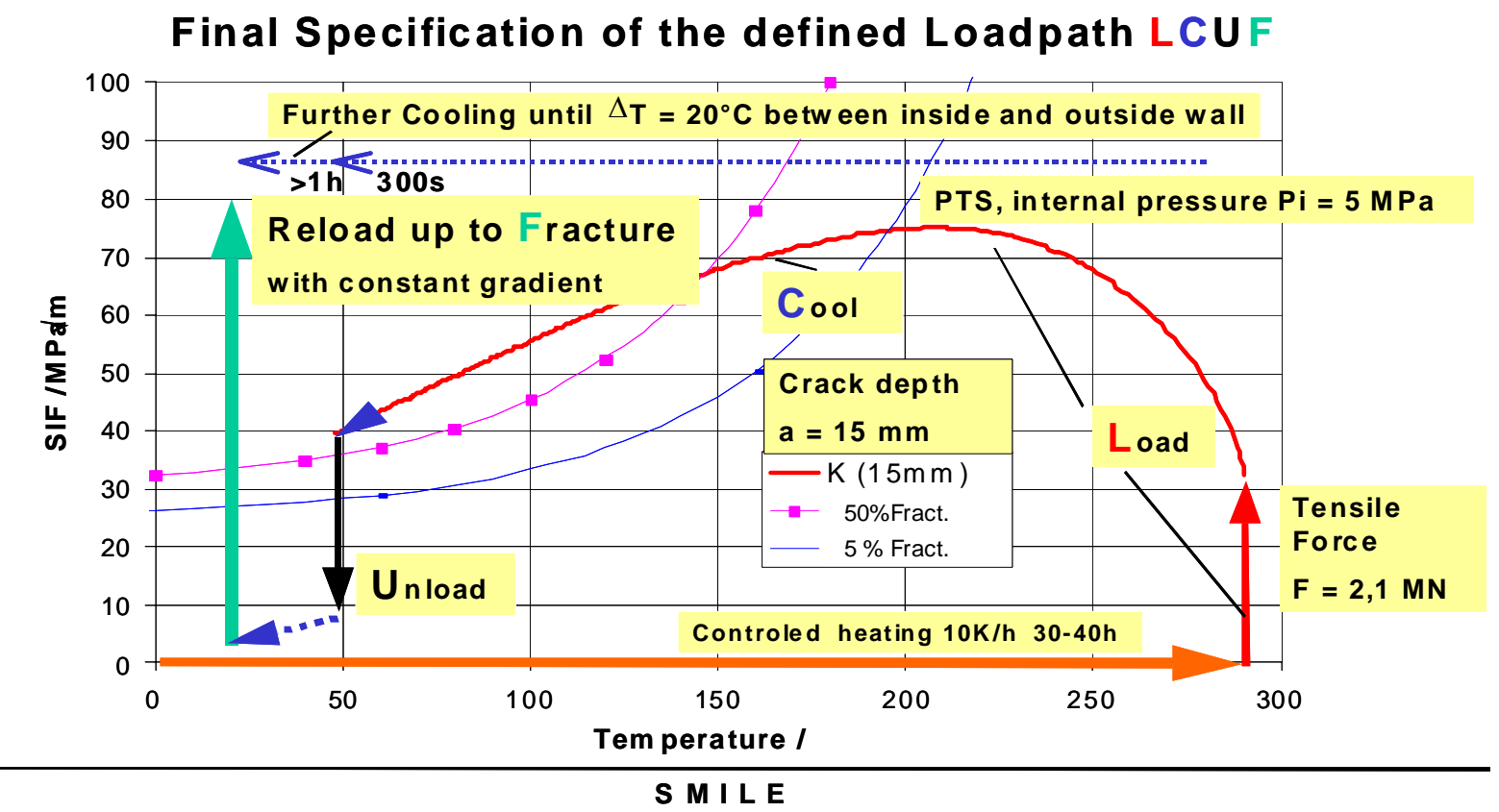

Fig. 3 - Schematic of WP4 'large scale' cracked cylinder experiment (17 MoV 84 mod.)

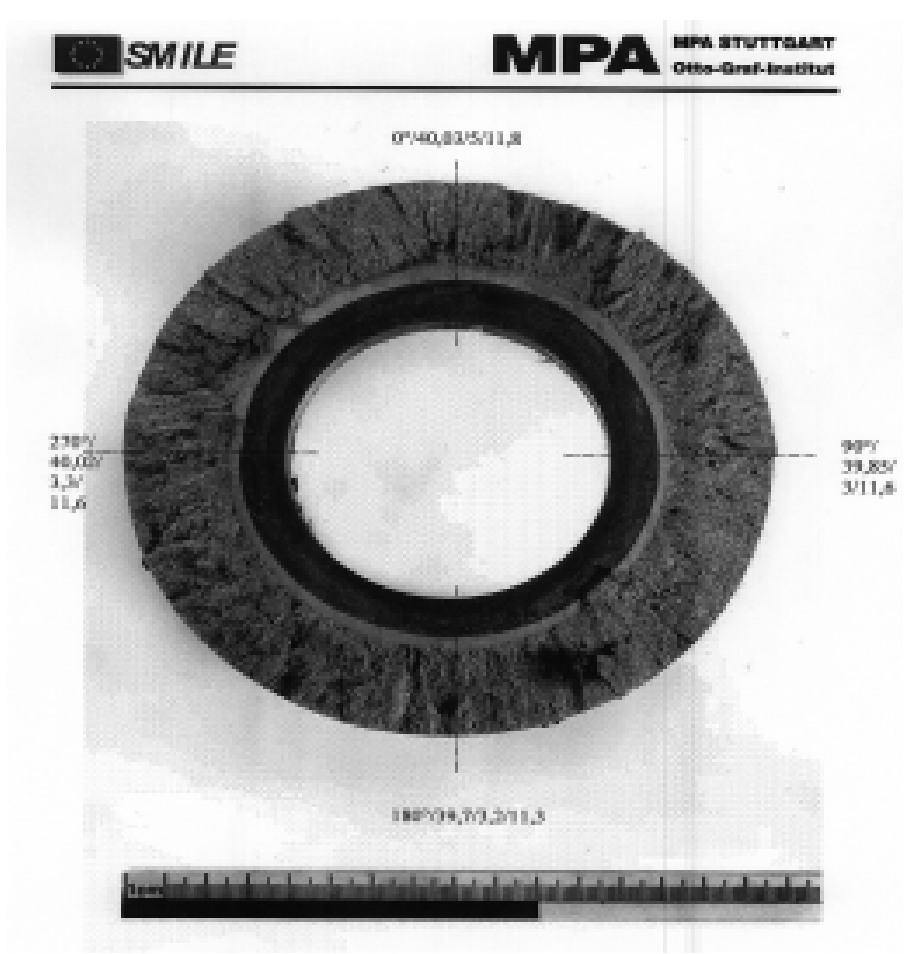

Fig. 4 - Brittle failure of the WP4 cylinder during final reloading 


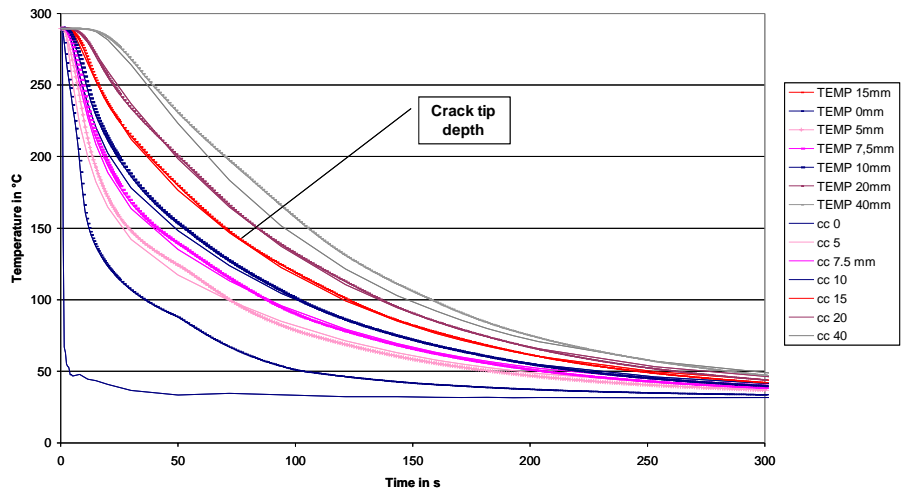

Fig. 5 - Experimental and simulated temperature versus time

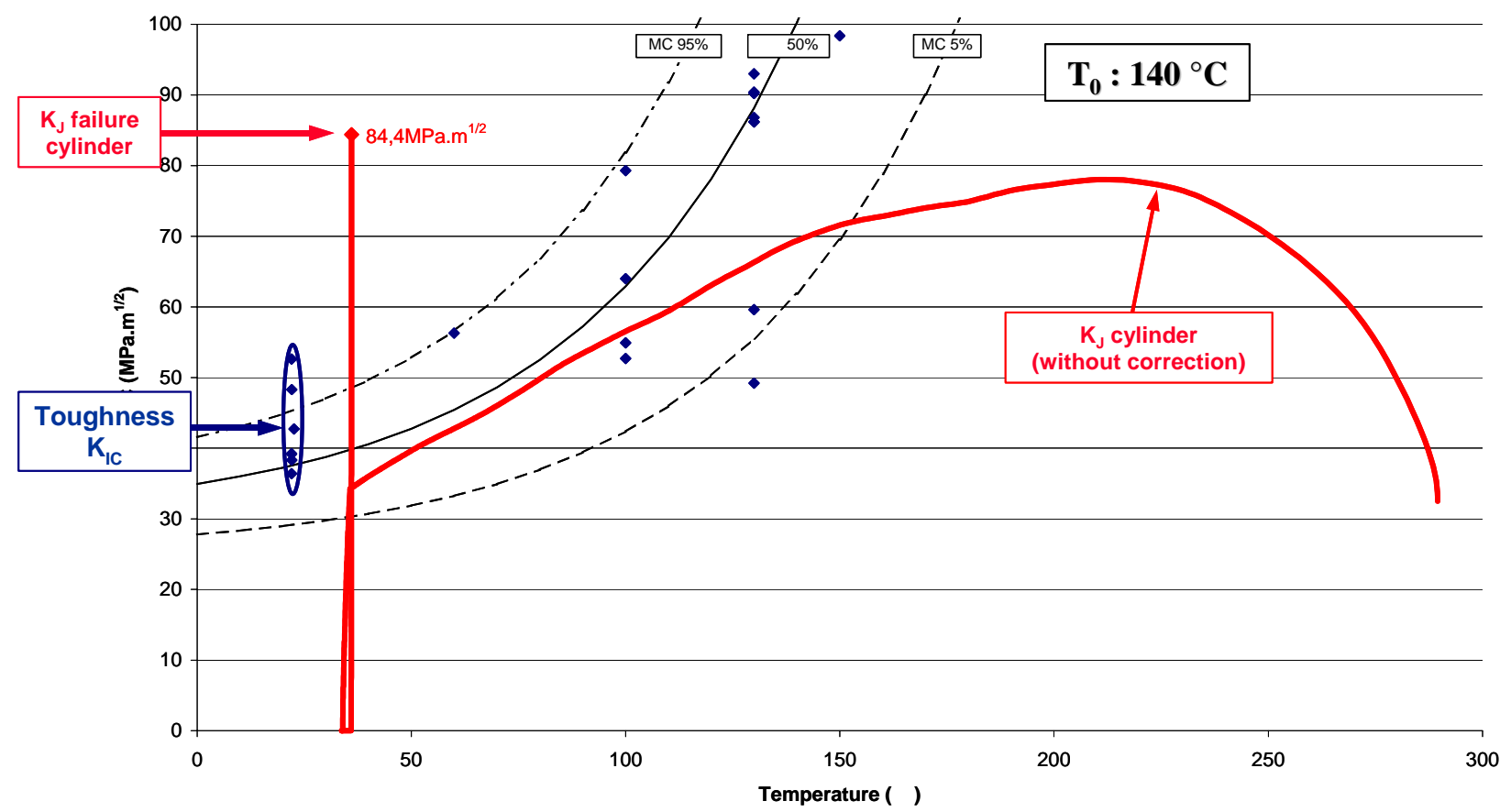

Fig. 6 -Comparison between $K_{J}$ and $K_{I c}$ (without size correction) 


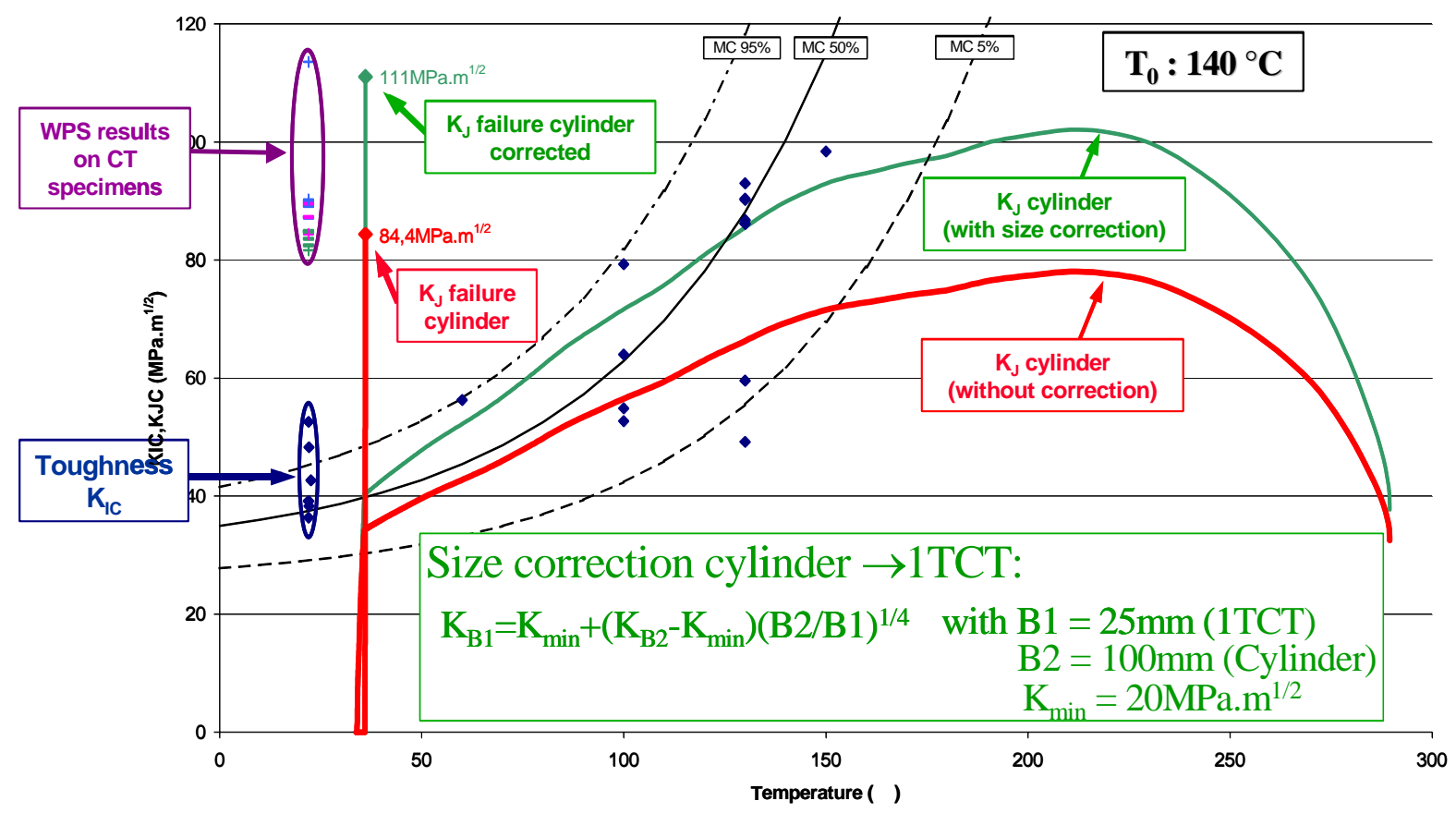

Fig. 7 - Comparison between $K_{I c}$ and $K_{J}$ (with size correction)

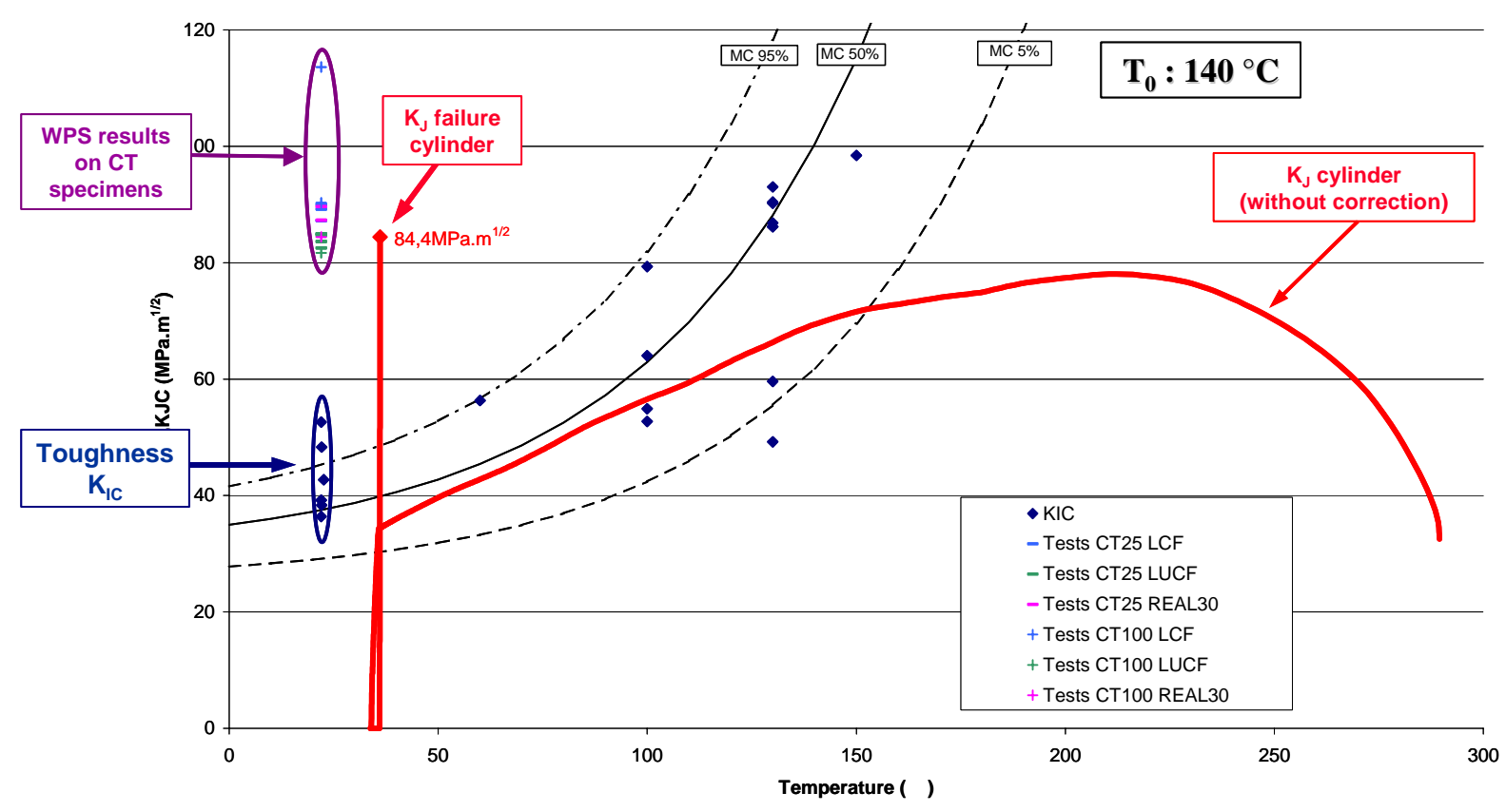

Fig. 8 -Comparison of WPS effect between the cracked cylinder and the WPS type CT specimens 


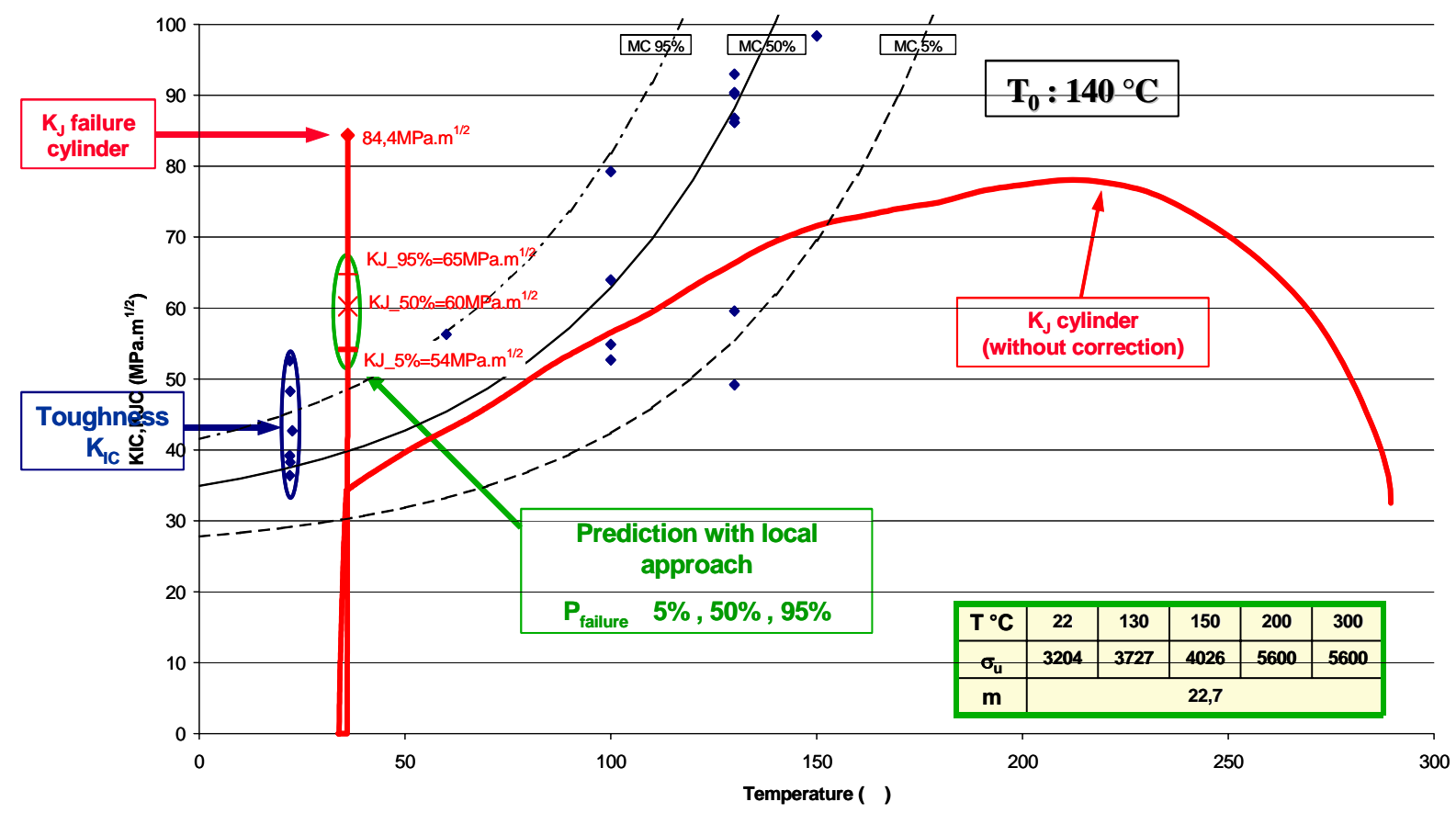

Fig. 9 - Application of 'modified' Beremin model (without size correction)

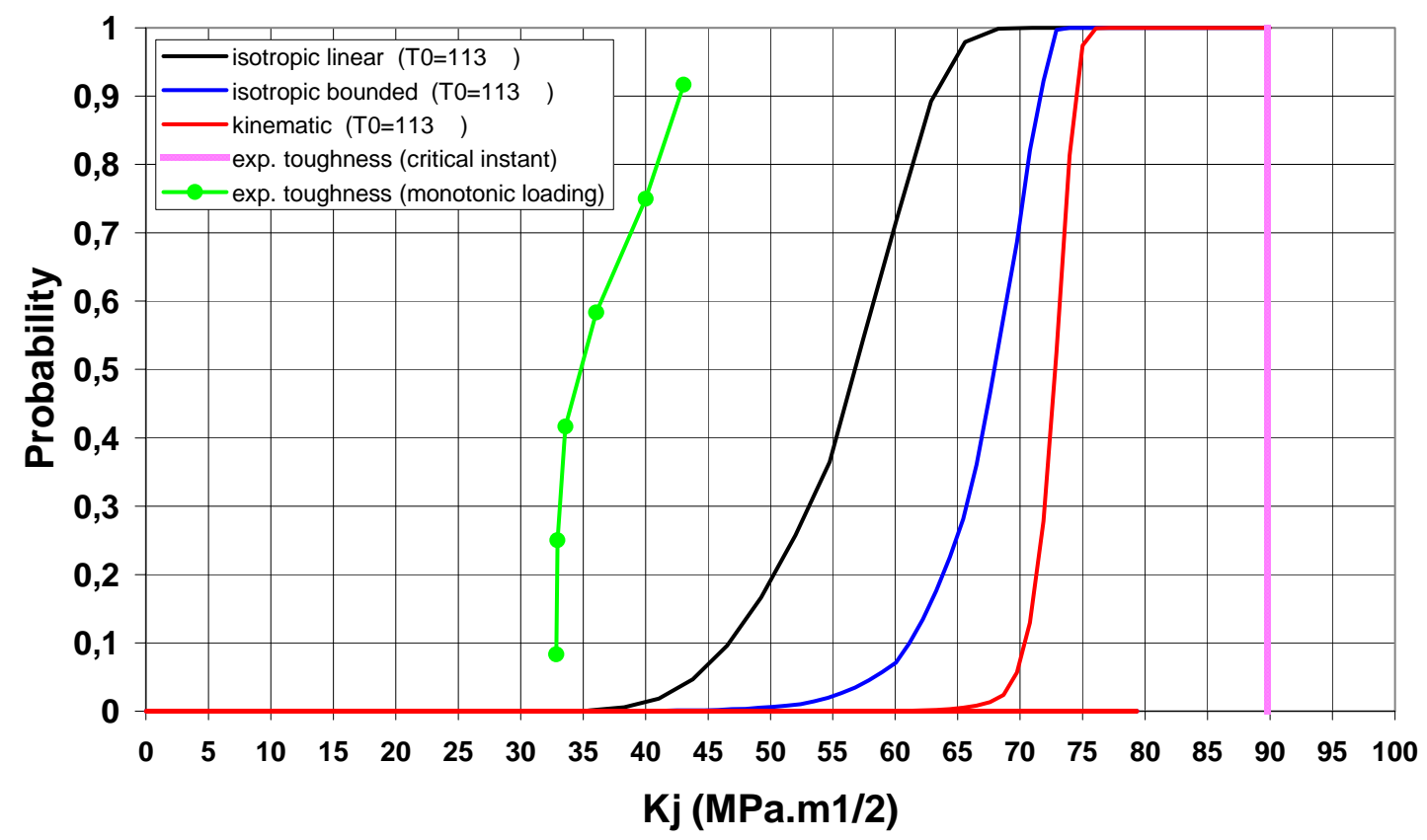

Fig. 10 - Failure probability as function of $K_{J}$, compared with experimental results (using Energy approach) 